\title{
Isotope fingerprinting of precipitation associated with western disturbances and Indian summer monsoons across the Himalayas
}

\author{
Ghulam JeElani ${ }^{1, *}$ and R D DeshPANDE ${ }^{2}$ \\ ${ }^{1}$ Department of Earth Sciences, University of Kashmir, Srinagar 190006, India. \\ ${ }^{2}$ Geosciences Division, Physical Research Laboratory, Navrangpura, Ahmedabad 380009, India. \\ *Corresponding author. e-mail: geojeelani@gmail.com
}

MS received 15 February 2016; revised 15 April 2017; accepted 27 May 2017; published online 22 November 2017

Precipitation samples were collected across the Himalayas from Kashmir (western Himalaya) to Assam (eastern Himalaya) to understand the variation of the stable isotopic content $\left(\delta^{18} \mathrm{O}\right.$ and $\left.\delta \mathrm{D}\right)$ in precipitation associated with two dominant weather systems of the region: western disturbances (WDs) and Indian summer monsoon (ISM). Large spatial and temporal variations in isotopic values were noted with $\delta^{18} \mathrm{O}$ and $\delta \mathrm{D}$ values ranging from -30.3 to $+9.3 \%$ and -228 to $+59^{\%} \%$, respectively. The d-excess values also exhibit a large range of variation from -30 to $+40 \%$. In general, heavier isotopic values are observed in most of the samples in Jammu, whereas lighter values are observed in majority of the samples in Uttarakhand. Precipitation at Jammu seems to have undergone intense evaporation while that from Uttarakhand suggest normal Rayleigh fractionation/distillation of the air mass as it moves from the source region to the precipitation site and/or orographic lifting. The d-excess of rainfall in Kashmir has a distinctly higher median value of $18 \%$ compared to other precipitation sites with a median of $9-12 \%$. Using distinct isotopic signatures, the regions receiving precipitation from two different weather systems have been identified.

Keywords. Isotopes; precipitation; western disturbances; Indian summer monsoons; Himalayas.

\section{Introduction}

The stable isotopes of oxygen and hydrogen have become an important tool not only in isotope hydrology, but also in studies related to atmospheric circulation and paleoclimatic investigations (Araguás-Araguás et al. 2000). The isotopic signature of precipitation provides valuable information about vapour source and atmospheric circulation pattern. In the modern environment, the isotopic composition of precipitation provides a conservative tracer for the origin, phase transitions, and transport paths of water (Dansgaard 1964;
Rozanski et al. 1993; Gat 1996). $\delta^{18} \mathrm{O}$ and $\delta \mathrm{D}$ of precipitation are dominantly controlled by atmospheric parameters such as temperature, relative humidity, and evaporation (Dansgaard 1964; Yurtsever and Gat 1981; Rozanski et al. 1993), and by geographic factors such as altitude, latitude, moisture source, and transport process (e.g., Craig 1961; Siegenthaler and Oeschger 1980; Gat 1996; Kendall and Coplen 2001). The deuterium excess, $d=\delta \mathrm{D}-8 \times \delta^{18} \mathrm{O}$ (Dansgaard 1964), a measure of deviation of data points from a line with slope 8 through VSMOW (Araguás-Araguás et al. 2000), is considered as an additional tool to iden- 
tify the moisture source, near surface relative humidity and the wind speed over the source (Marlivat and Jouzel 1979; Jouzel and Merlivat 1984; Johnsen et al. 1989). Recycling of moisture to the atmosphere increases the dexcess of the atmospheric vapour and consequently of the precipitation formed by condensation of this vapour. High $d$ values $(\sim 20 \%)$ are found in vapour generated under low relative humidity conditions, e.g., vapour generated at the Mediterranean Sea (Gat and Carmi 1970). The western disturbances (WDs) and the Indian summer monsoon (ISM) are the two dominant weather systems of the Himalayas. These airflows are responsible for the bulk of the Himalayan precipitation. The flow of the Himalayan rivers is primarily dependent upon the strength, behaviour and duration of WDs and ISM. The WDs are synoptic weather systems that propagate eastward from the Mediterranean region towards south Asia (Madhura et al. 2015). These are embedded in the sub-tropical Westerlies, which often extend down to lower atmospheric levels over the north Indian latitudes and produce significant rainfall over western Himalayas and northern India during DJFMA (Pisharoty and Desai 1956). WDs are active across western Himalaya during the summer months as well, when their frequency reduces significantly (Dhar et al. 1984; Dimri et al. 2004). The ISM develops in response to the movement of the Inter Tropical Convergence Zone (ITCZ) that separates wind circulation of the northern and southern hemispheres (Gadgil 2003). Arabian Sea and the Bay of Bengal are the two principal sources of oceanic vapour to the Indian subcontinent during ISM (Das 2005). ISM remains active from June/July to September (Rao 1976). Post - ISM the precipitation in eastern Himalayas may be caused due to the atmospheric disturbances over the Bay of Bengal. It is important to understand the observed spatial and temporal isotopic variation in precipitation across the Himalayas in terms of the geographical extent of influence and the contributing moisture source. The main objective of this study is to assess the variability in $\delta^{18} \mathrm{O}$ and $\delta \mathrm{D}$ of precipitation associated with WDs and ISM (figure 1).

\section{Methodology}

Precipitation samples were collected across the Himalayas (table 1, figure 1) from Kashmir in the western Himalaya to Assam in the eastern Himalaya for the analysis of $\delta^{18} \mathrm{O}$ and $\delta \mathrm{D}$. Most of the precipitation samples for this study were collected under the aegis of the National Program (IWIN) for Isotope Fingerprinting of Waters of India (Deshpande and Gupta 2012). Monthly composite samples were collected in Kashmir (from 5 sites), Himachal Pradesh (2 sites), Uttarakhand (4 sites) and Assam (3 sites) in 2009 and 2010. All these samples were analyzed using IWIN-IRMS facility at Physical Research Laboratory (PRL), Ahmedabad, following standard equilibration method in which water samples were equilibrated with $\mathrm{CO}_{2}\left(\right.$ or $\left.\mathrm{H}_{2}\right)$ and the equilibrated $\mathrm{CO}_{2}$ (or $\mathrm{H}_{2}$ ) gas was analyzed in Delta V Plus (IRMS) in continuous flow mode using Gasbench II (Maurya et al. 2011). Some of the published data was also used to understand the synoptic view and behaviour of isotopes in precipitation across the Himalayas; 15 precipitation sites from Kashmir (Jeelani et al. 2010, 2013), 10 sites from Uttarakhand (Kumar et al. 2010; Rai et al. 2014), 01 site from Nepal (Gajurel et al. 2006) and 01 site from Meghalaya (Breitenbach et al. 2010). IMD, New Delhi from its sub-offices, provided the meteorological data.

\section{Results and discussion}

\subsection{Variation of stable isotopes and d-excess in precipitation}

Large variations in isotopic values were noted spatially and temporally across the Himalayas (figures $2-4)$ with $\delta^{18} \mathrm{O}$ and $\delta \mathrm{D}$ values ranging from -30.3 to $+9.3 \%$ and -228 to $+59 \%$, respectively. The d-excess values also exhibit a large range of variation from -30 to $+40 \%$. The lowest $\delta^{18} \mathrm{O}$ and $\delta \mathrm{D}$ values are mostly found in Uttarakhand and the highest values in Jammu. There is no systematic and contiguous geographical trend in the variability of isotopic composition across the length of Himalayas (figure 2). However, there are subtle aspects of the isotopic variation at different stations, together with oscillating behaviour from west to east, which can be ascribed to interplay of complex hydro-meteorological processes operating in the Himalayan region. The variation of stable isotopes in precipitation across the Himalayas is discussed under the following heads: 


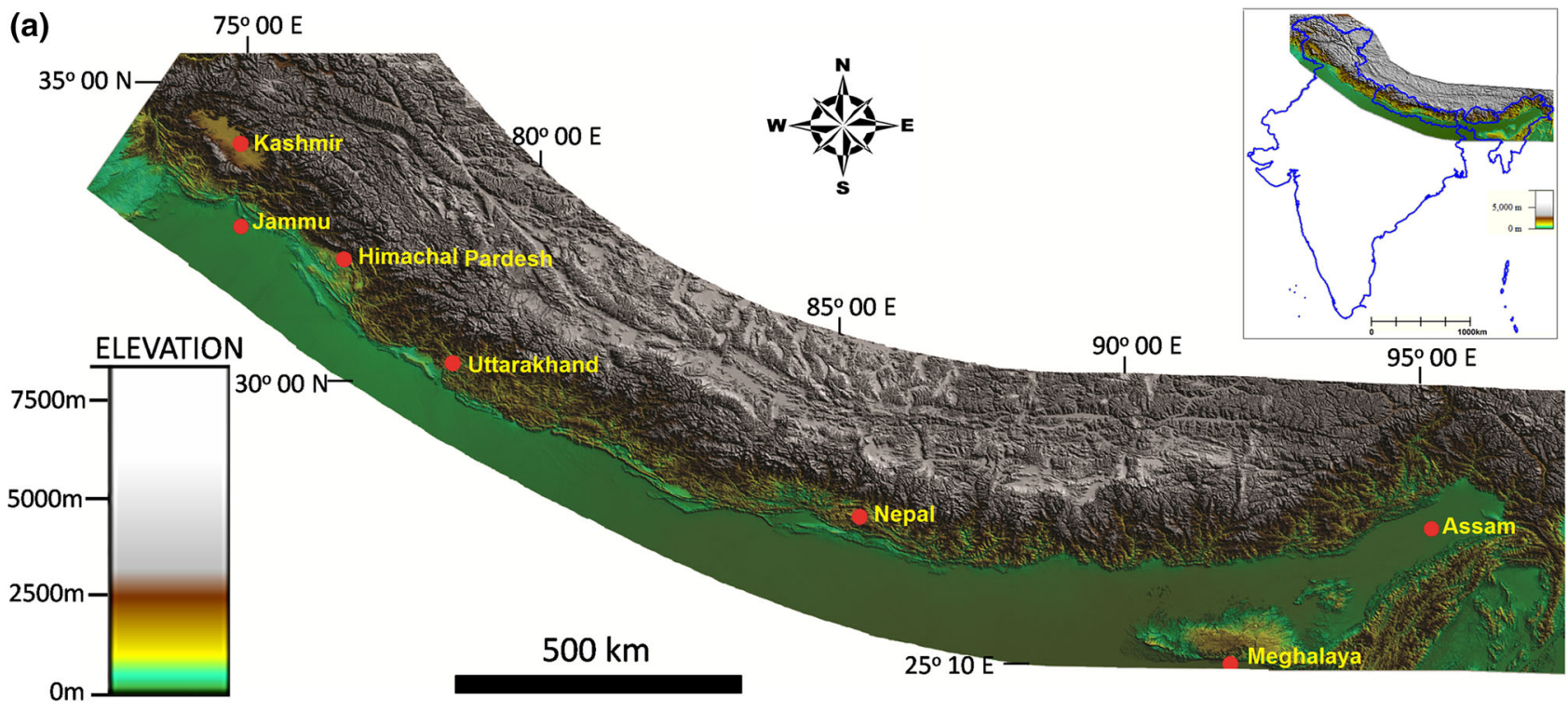

(b)

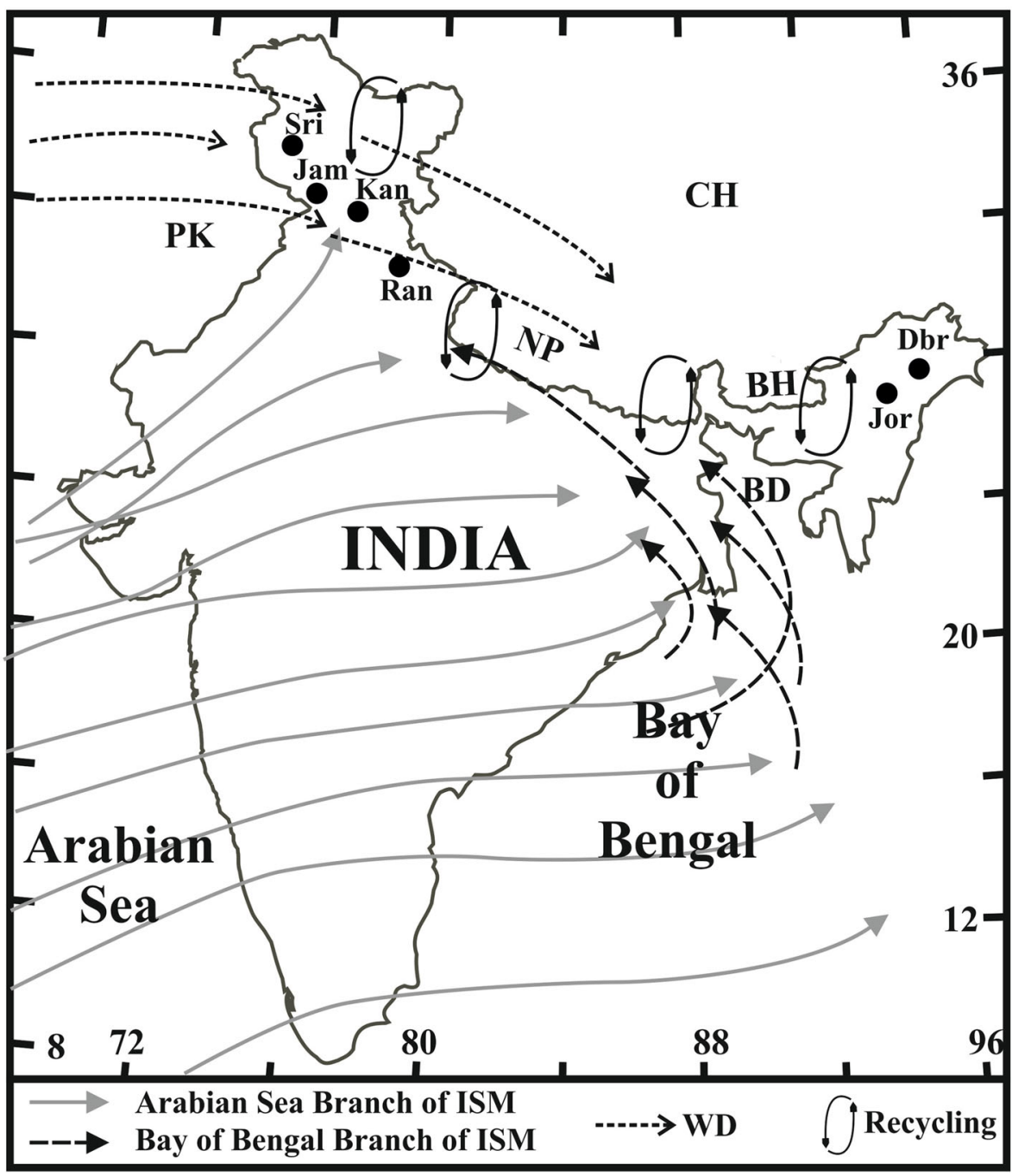

Figure 1. (a) Locations of the sampling regions across the Himalayas. (b) Map of India showing schematic circulation pattern of Arabian Sea branch of the ISM, Bay of Bengal branch of ISM, Western Disturbances and the local recycling. 


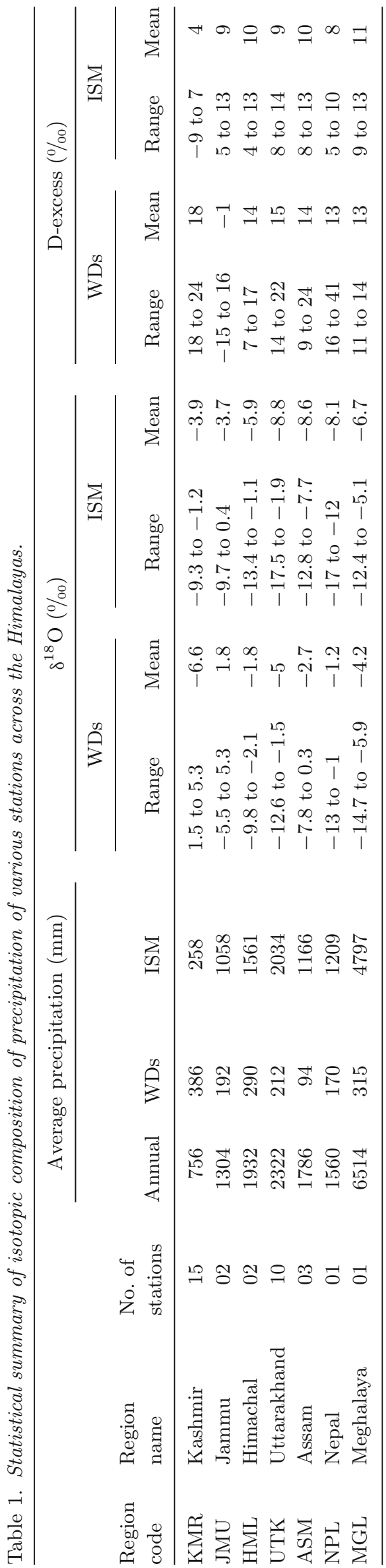

\subsubsection{Spatial variation in isotopic characteristics}

Spatially, the Himalayan precipitation shows large range in isotopic values. Despite large variability in isotopic composition of monthly composite precipitation, about $20 \%$ samples showed similar isotopic signature across the Himalayas $\left(\delta^{18} \mathrm{O}:-5.7\right.$ to $-4.3^{\circ} \%$ and $\delta \mathrm{D}:-35$ to $-21 \%$. The heavier isotopic values (w.r.t. this common signature) are observed in most of the samples $(>60 \%)$ in Jammu (most enriched in heavier isotopes), Himachal and Nepal, whereas lighter isotopic values are observed in majority of the samples $(>50 \%)$ in Uttarakhand (most depleted in heavier isotopes), Kashmir, Assam and Meghalaya. The samples with heavier isotopic values indicate the effect of differential degree of evaporation, with most intensive evaporation at Jammu station. A significant inverse correlation exist between average monthly $\delta^{18} \mathrm{O}$ and $\mathrm{d}$-excess of precipitation at Jammu station $\left(R^{2}=0.85\right.$ and $\left.p<0.05\right)$. The most depleted values observed in samples suggest the normal Rayleigh fractionation/ distillation of the air-mass as it moves from the vapour source region to the precipitation site and/or orographic lifting. The observed isotopic depletion in Uttarakhand may be ascribed to lower temperature owing to its high altitude $(\sim 2200 \mathrm{~m})$. Isotopic compositions of precipitation northwest of Uttarakhand are not found to be lighter. This suggests that in the Himalayas, further northwest of Uttarakhand, there is either a different meteorological regime and/or significant admixture of transpired vapour in the region.

The d-excess of about $35 \%$ of precipitation samples across the Himalayas show narrow range $(10-13 \%$ ) except Kashmir, where only $\sim 10 \%$ samples fall in this category. The d-excess of rainfall in Kashmir has a distinctly higher median value of $18 \%$ compared to other precipitation sites with a median of $9-12 \%$. This indicates at least two dominant and isotopically distinguishable sources of precipitation, viz., WDs and ISM. It is observed that the d-excess of precipitation NW of Uttarakhand show much larger variability compared to the precipitation towards east of Uttarakhand, except in Assam. A large range of variation in d-excess (figure 2) observed in Assam (eastern Himalayas), Jammu, Kashmir and Himachal Pradesh (western Himalayas) suggest contribution of vapour from secondary sources: local recycling, evaporation of falling raindrops, etc. In Assam, being nearer to 

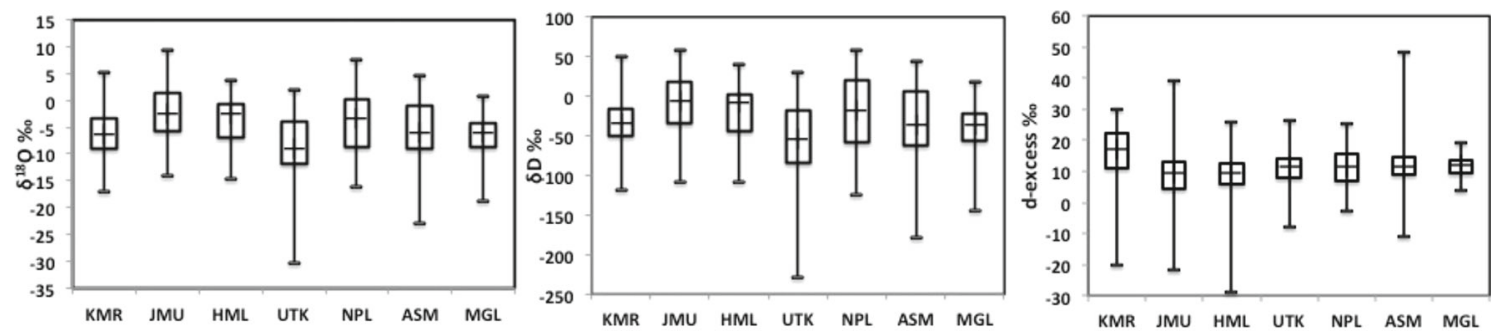

Figure 2. Box and Whisker plots showing minimum, first quartile (Q1), median, 3rd quartile (Q3) and maximum values of $\delta^{18} \mathrm{O}, \delta \mathrm{D}$ and d-excess in annual precipitation across the Himalayas depicting spatial variation in the isotopic characteristics. The horizontal axis represents different regions: KMR (Kashmir), JMU (Jammu), HML (Himachal Pradesh), UTK (Uttarakhand), NPL (Nepal), ASM (Assam), and MGL (Meghalaya).
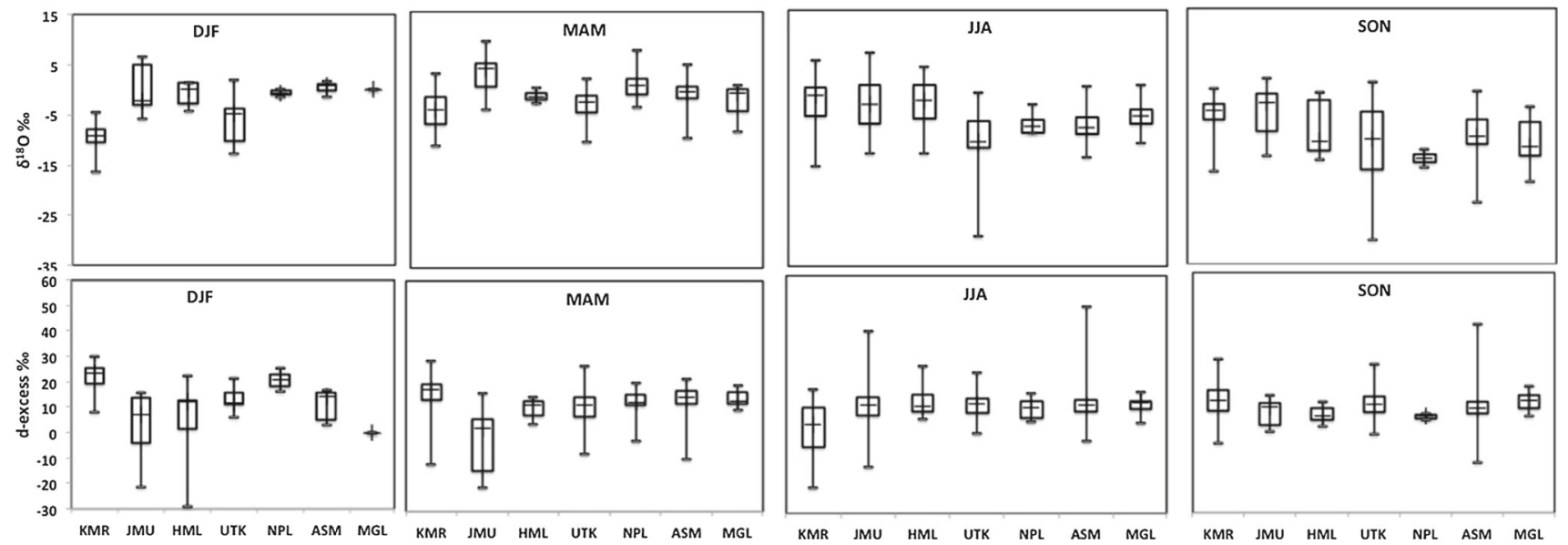

Figure 3. Box and Whisker plots showing minimum, first quartile (Q1), median, 3rd quartile (Q3) and maximum values of $\delta^{18} \mathrm{O}$ and d-excess in seasonal (DJF: Dec-Jan-Feb; MAM: Mar-Apr-May; JJA: Jun-Jul-Aug; SON: Sep-Oct-Nov) precipitation across the Himalayas. Horizontal axis represents different regions; KMR (Kashmir), JMU (Jammu), HML (Himachal Pradesh), UTK (Uttarakhand), NPL (Nepal), ASM (Assam), and MGL (Meghalaya).

the Bay of Bengal, the d-excess similar to that of Meghalaya is expected, which is not the case. The eastern Himalayas receive precipitation from the Bay of Bengal branch of the ISM (Das 2005). The increase in d-excess in $25 \%$ of the samples in Assam (Q3 to maximum) and its large variation from 15 to $48 \%$ (highest d-excess) indicates the possibility of local recycling, long distance transport of vapour and/or the source of precipitation from WDs. However, decrease in d-excess associated with increase in $\delta^{18} \mathrm{O}$, in $25 \%$ of the samples (Q1 to minimum) in Kashmir and its large variation from 11 to $-20 \%$ indicates the possibility of evaporation of falling rain and/or the source of precipitation from ISM. Similarly, $25 \%$ of the samples in Himachal Pradesh and Jammu also indicate the effect of evaporation on precipitation. The high d-excess $(>12 \%)$ of most $(50 \%)$ of the samples from Nepal station suggests local recycling, long distance transport of vapour and/or the sources of precipitation from WDs.

\subsubsection{Temporal variation in isotopic characteristics}

The highest d-excess is observed in Kashmir in December-February (DJF); $75 \%$ of the samples (figure 3; between Q1 and maximum) have very high d-excess of $\geq 20 \%$, while only $3 \%$ of the samples have d-excess of $<15 \%$. Higher d-excess (than global average of $\sim 10 \%$ ) is also observed in $75 \%$ of the samples (between Q1 and maximum) in Uttarakhand (d-excess $>12 \%$ ) and Nepal (d-excess $>16 \%$ oo though the values are lower compared to Kashmir. Moderately high d-excess $(>14 \%)$ is observed in $50 \%$ of the samples in Assam. Lowest d-excess is observed in Jammu, Himachal and Meghalaya in DJF. As we know that WDs are dominant during this period (DJF), the results suggest that the moving air mass undergo a lot of modifications from west to east Himalayas. High d-excess in precipitation in Kashmir during the months of DJF suggests contribution of vapour 


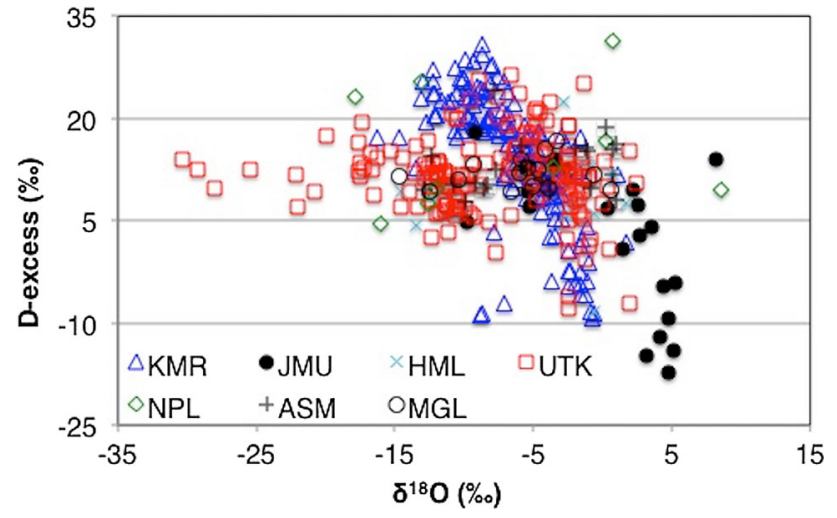

Figure 4. Relationship between $\delta^{18} \mathrm{O}$ and d-excess of average monthly precipitation across the Himalayas.

generated under relatively lower relative humidity, much less than global average value of $80 \%$ for most of the oceans and $75 \%$ over most of the land surfaces, excluding dry areas (Dai 2006). During the months of DJF, the WDs are responsible for long distance transport of vapour generated from Mediterranean Sea or Caspian Sea under lower relative humidity. Vapour generated under lower relative humidity condition, such as that in Mediterranean region, is known to have high d-excess of around 20\% (Gat and Carmi 1970). Due to long distance transport of such an air parcel over the continent, its isotopic composition is expected to change from its initial value due to various processes like picking up of locally recycled vapour, rainout effect, etc. Relatively depleted isotopic composition and high d-excess (around 15\%) is observed in the northeast monsoon rainfall in Kerala, located in southern part of India compared to the ISM rains of this station. This was attributed to the long distance transport of the northeast monsoon currents over continental region (Deshpande et al. 2003; Warrier et al. 2010). However, contrary to this, in the present study, it was noticed that during the period of WDs the ambient temperatures are low (average monthly regional temperature ranges from 8 to $14^{\circ} \mathrm{C}$ ) and the contribution of local moisture to precipitation may be less. Therefore, there may be a little isotopic modification of residual vapour mass transported from Mediterranean region to the study area.

In Jammu and Himachal Pradesh, the d-excess decreases in DJF, which is also associated with the increase in $\delta^{18} \mathrm{O}$ (enriched ${ }^{18} \mathrm{O}$ ) indicating the evaporation of rain. The observed high d-excess $(\sim 20 \%)$ during DJF in Uttarakhand, Nepal and farther east in Assam suggest the vapour generated under lower relative humidity condition, i.e., the influence of WDs. However, it needs to be ascertained if this high d-excess in precipitation signifies the influence of WDs in the central and eastern Himalayas or significant local recycling of vapour. In Uttarakhand, in DJF, higher d-excess (w.r.t. other stations except Kashmir), associated with low $\delta^{18} \mathrm{O}$ (depleted ${ }^{18} \mathrm{O}$ ) suggests the dominant influence of WDs without the significant effect of evaporation. In Nepal and Assam, the high d-excess $(\sim 20 \%)$ is associated with high $\delta^{18} \mathrm{O}$ (enriched ${ }^{18} \mathrm{O}$ ) possibly suggesting dominant influence of transpiration, which tends to increase $\delta^{18} \mathrm{O}$ of vapour over the forest floor (Lai and Ehleringer 2010) or the influence of WDs with evaporation.

From June to August (JJA), when ISM is dominant, the d-excess of $\geq 8 \%$ is observed in $75 \%$ of the samples (between Q1 and maximum) across the Himalayas (except Kashmir) and $>6 \%$ d-excess is also observed in Nepal (75\% samples). The lowest $\delta^{18} \mathrm{O}$ is observed in Uttarakhand in JJA. The $\delta^{18} \mathrm{O}$ values are seen to progressively decrease from Meghalaya in the eastern Himalayas up to Uttarakhand in the central Himalayas. Further west of Uttarakhand, the $\delta^{18} \mathrm{O}$ values increase at Himachal, Jammu and Kashmir. This suggests that up to Uttarakhand in central Himalayas, the moisture regime is dominated by the primary marine source, most likely the Bay of Bengal. Further west of Uttarakhand, there seems to be significant admixture of evapotranspired vapour. However, at these stations west of Uttarakhand, the d-excess is not very high. This suggests that vapour admixture is due to transpiration and not the evaporation, which would have manifested in high d-excess as well. The lowest and distinguishable d-excess in Kashmir during June to September is associated with high $\delta^{18} \mathrm{O}$, that is almost similar to that of Jammu and Himachal, which suggests either different source of moisture during this period and/or the admixture of locally derived moisture with that transported through ISM. It is already an established fact that BOB moisture contributes to precipitation in Himalayas. Medina et al. (2010) have shown using Tropical Rainfall Measuring Mission (TRMM) Precipitation Radar (PR) data that convective systems containing broad stratiform radar echoes occur in the eastern Himalayas in association with BOB depressions, as strong lowlevel flow transports maritime moisture into the Himalayan region. In the course of its passage 
over the Bangladesh wetlands, additional moisture is extracted from the diurnally heated surface. Convection is triggered as conditionally unstable flow is lifted upstream of and over the foothills. The convective cells evolve into mesoscale convective systems with convective and stratiform areas. These mesoscale convective systems are advected farther into the Himalayan eastern indentation, where orographic lifting enhances the stratiform precipitation.

In Jammu, the lowest d-excess $(\leq 6 \%)$ is observed in $75 \%$ of the samples (between Q3 and minimum) from March to May, which is the lowest among all the locations across Himalayas and also among all the four seasons. The low dexcess is associated with highest $\delta^{18} \mathrm{O}$ (enriched ${ }^{18} \mathrm{O}$ ) suggesting that falling raindrops in Jammu region experience maximum evaporation during the fall from cloud base to ground level. The effect of evaporation is also discernible here in other seasons as well (figure 3). Monthwise distribution of $\delta^{18} \mathrm{O}$ and d-excess of monthly composite samples (figure 4) shows that at each station, in different seasons, there are some precipitation samples with extremely high or low values of $\delta^{18} \mathrm{O}$ and d-excess which lie outside the normal range (mean $\pm 1 \mathrm{SD}$ ) of variation at that station. This indicates significant role of sporadic hydrometeorological processes in modifying the isotopic composition of such isotopically extreme events which include moisture recycling, sub-cloud evaporation, local/regional convection over land area, etc. Among all the stations, Assam is conspicuous by a large range of variation in d-excess and intermittent rain events with very high d-excess values observed almost throughout the year (figures 3-4), except in MAM. The high d-excess of precipitation with low isotopic value in Assam during DJF can possibly be interpreted as the farther eastward excursion of WDs. Although influence of WDs so much farther in the eastern Himalayas has not been clearly reported earlier, the high d-excess in the Ganga River at Rishikesh in central Himalayas has earlier been ascribed to WDs (Maurya et al. 2009). Madhura et al. (2015), Agnihotri and Singh (1982) and Dimri et al. (2004) also suggested influence of WDs in the western Himalaya and the north of India during winter. Similar high d-excess observed even during June to November months covering southwest and northeast monsoon seasons is unusual. The influence of WDs in Assam cannot be hypothesized during June to November months; therefore, an alternate mechanism for observed high d-excess in rain events at Assam during June to November (JJA and SON) period could be the local recycling. It is to be noted here that in Assam, 9.7\% (764,373 ha) of the total area is under wetlands including rivers, streams and riverine wetlands; and the open pan annual evaporation $(2.36 \mathrm{~mm} /$ day $)$ and annual potential evapotranspiration $(3 \mathrm{~mm} /$ day) at Jorhat in Assam is lowest in the country (Rao et al. 2012). The relative humidity is higher during summer months from June to November. The low values of open pan and potential evapotranspiration and high relative humidity in Assam suggest that atmosphere remains continuously loaded with locally generated moisture during summer months. This recycled moisture seems to mix with vapour advected by monsoonal winds and results in rains with high d-excess during June to November. In contrast, during the winter season (DJF), the low relative humidity increases the chances of evaporation of the light rain events. Lesser rainfall (32 $\mathrm{mm})$, warm temperatures $\left(22^{\circ} \mathrm{C}\right)$ and enriched isotopic values than the other seasons (figure 3) in Assam corroborate the evaporation of falling raindrops.

In contrast to low evapotranspiration in Jorhat (Assam) in eastern Himalaya, the estimated evapotranspiration in Jammu in the western Himalayan region is quite high (Nikam et al. 2014), with values varying from $6.5 \mathrm{~mm} /$ day in May, $6.0 \mathrm{~mm} /$ day in June, $4.5 \mathrm{~mm} /$ day in July, $3.9 \mathrm{~mm} /$ day in August, $4.0 \mathrm{~mm} /$ day in September, $3.6 \mathrm{~mm} /$ day in October and $2.6 \mathrm{~mm}$ /day in November. Due to such a high evaporation demand of atmosphere, the raindrops often undergo significant evaporation during their fall from cloud base to ground. This is manifested in the form of very low d-excess values for several precipitation samples at Jammu almost throughout the year.

\section{$3.2 \delta^{18} O-\delta D$ regression lines}

The slope of the annual $\delta^{18} \mathrm{O}-\delta \mathrm{D}$ regression lines (table 2) increases from western Himalayas (Kashmir: 7.1; Jammu: 6.8) to the eastern Himalayas (Assam: 8.2; Meghalaya: 8.1). Except for Jammu and Kashmir, the slopes of regression line for all other stations, i.e., from Himachal Pradesh to Meghalaya, are nearly the same with a very narrow (0.3) range of variation. This suggests the possible existence of two dominant but different hydro-meteorological regimes in Himalayas, namely: (i) from Meghalaya to Himachal Pradesh covering majority of eastern length of Himalayas; 


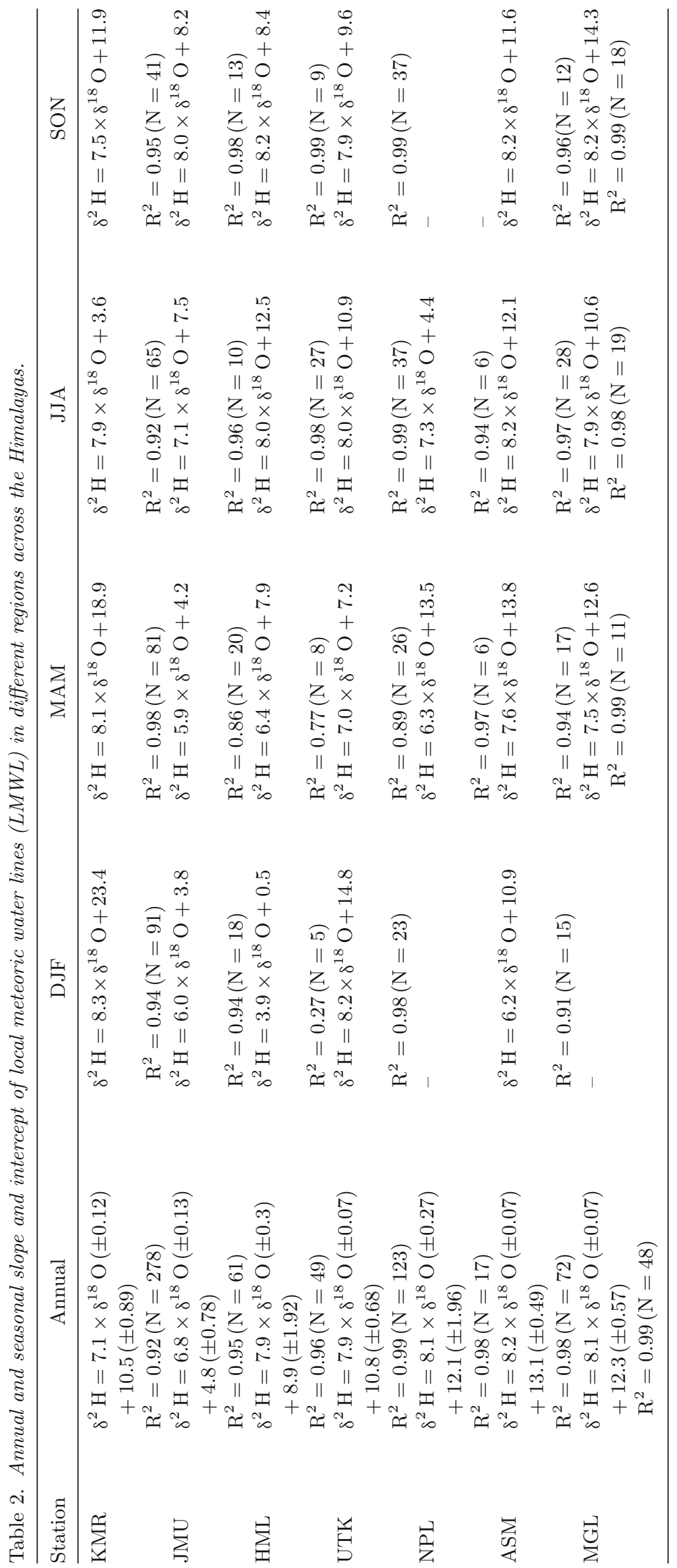


and (ii) Jammu and Kashmir in the western part of Himalayas. These two regions have also been identified earlier based on $\delta^{18} \mathrm{O}$ and d-excess values. Annually highest intercept (table 2) is observed in Assam and lowest in Jammu. Significantly higher intercept is observed in Kashmir during DJF and MAM, indicating influence of vapour generated under low humidity extra-tropical region and transported under the influence of WDs. In DJF, high intercept is also observed farther southeastward regions of Uttarakhand and Nepal. This suggests the possible influence of extra-tropical vapour in the rainfall at much farther southeastward beyond western Himalayas. During months of DJF, intercept in Assam (10.9) is much lower than that in Uttarakhand (14.8), which suggest the influence of extra-tropical vapour. However, the regression line slope at Assam for DJF is much smaller (6.2) compared to GMWL as well as that at Uttarakhand (8.2), indicating evaporation of raindrops; consequently, the observed intercept may not be the pristine signature and the influence of extra-tropical vapour cannot be completely ruled out. The intercept in Assam and Meghalaya for most of the year (i.e., MAM, JJA, SON) is higher (table 2) compared to GMWL and also compared to the other Himalayan stations in the northwest. This suggests that considerable vapour recycling throughout the year influences eastern extreme of Himalayas. Rainfall in Jammu for most part of the year (except the months SON) has slope (5.9-7.1) and intercept (3.6-23.4) that indicate that rainfall here undergoes significant evaporation before reaching the ground. This possibility is also supported from the fact that relative humidity at Jammu is consistently low $(<40 \%)$ throughout the year.

From the isotopic characteristic $\left(\delta^{18} \mathrm{O}, \delta \mathrm{D}, \mathrm{d}-\right.$ excess, regression line slope and intercept; figures 2-4 and table 2) of precipitation, it is evident that the Himalayan region from Himachal Pradesh to Meghalaya is influenced primarily by a common marine vapour, originating from the Bay of Bengal and/or the Arabian Sea, being transported through seasonal reversing of winds from winter to summer monsoons. On the other hand, it seems that western extreme of Himalayan region (Kashmir) is primarily influenced by vapour with high d-excess, generated under lower relative humidity, and transported through WDs. Being the area outside the monsoon regime, Kashmir is known to get rainfall from extra-tropical systems like WDs and trough in the Westerlies (Ranade et al. 2007). While extra- tropical source of vapour for rainfall in Kashmir is evidently recorded in isotopic composition of precipitation, the same is not possible in case of Jammu because of significant modification of pristine isotope characteristic due to evaporation. The lower slope (6.8) and intercept (4.8) along with lower d-excess at Jammu clearly indicate significant evaporation of falling rain drops (table 2). Since the pristine d-excess value of precipitation at Jammu is modified due to evaporation of raindrops, it is not possible to ascertain whether vapour source for rain at Jammu is principally monsoonal or extratropical. This study also highlights the possibility of influence of extra-tropical vapour through WDs, farther southeastward than just Kashmir. Consistently higher d-excess in Assam, almost throughout the year, indicates significant continental recycling of vapour and the influence of WDs in the southeastern end of Himalayas. Monthly composite sample being a mixture of several precipitation events, possibly of different origins, may not be the best option to explain the finer isotopic signatures associated with individual rain events under WDs and ISM. Nonetheless, monthly composite samples can provide broad isotopic signatures to distinguish between the rainfall under WDs and ISM which can be further refined by detailed event based sampling in future. However, monthly composite samples can give us the signature of the dominant precipitation event. In order to better understand the isotopic signatures associated with WDs and ISM, a detailed event-based sampling is required.

\subsection{Controlling factors}

Temperature, amount of precipitation, altitude, latitude, longitude and distance of sampling location from the sea, possible vapour source and typical rainout history of the air parcel are known as various factors influencing the isotopic composition of precipitation at a particular location. Except Jammu and Meghalaya, average $\delta^{18} \mathrm{O}$ of the precipitation of all regions showed a good relationship with the average ambient temperature from December/January to May/June (figure 5). As the temperature rise, the $\delta^{18} \mathrm{O}$ value of precipitation increases, with the highest correlation recorded in Kashmir $\left(r^{2}=0.58\right)$. In Jammu, the higher $\delta^{18} \mathrm{O}$ values during this period seems to be due the lower rainfall and low relative humidity, which promotes evaporation. However, the precipitation of all the regions showed decrease in $\delta^{18} \mathrm{O}$ from 
June/July to September/October despite higher ambient temperatures (figure 5). The apparent decrease in $\delta^{18} \mathrm{O}$ of precipitation, although coincides with higher precipitation amount, may be attributed to the change in the source of precipitation, as the correlation between the precipitation amount and the $\delta^{18} \mathrm{O}$ of precipitation is statistically insignificant. In order to quantify the possible influence of various controlling factors in the Himalayas, each sample with lower (L), normal $(\mathrm{N})$ or higher $(\mathrm{H})$ values of $\delta^{18} \mathrm{O}$, and lower (l), normal $(\mathrm{n})$ or higher $(\mathrm{h})$ values d-excess were categorized in to nine classes (Ll, Ln, Lh, Nl, Nn, $\mathrm{Nh}, \mathrm{Hl}, \mathrm{Hn}, \mathrm{Hh}$ ) based on the combination of their $\delta^{18} \mathrm{O}$ and $\mathrm{d}$-excess values (table 3 ). The range of normal values were taken as (average $\pm 1 \mathrm{SD}$ ) for each location. The values above this range were considered as higher values and values below this range were considered as lower values. The statistical treatment shows that most of the precipitation samples $(\sim 52 \%)$ fall in $\mathrm{Nn}$ (normal $\delta^{18} \mathrm{O}$ with normal d-excess) category followed by Ln (16\%) and Hn (14\%). There are only a few precipitation samples in $\mathrm{Ll}(1 \%)$ and $\mathrm{Hh}(1 \%)$ category. $\delta^{18} \mathrm{O}$ of $\mathrm{Nl}$ category shows better correlation with temperature $\left(r^{2}=0.47\right)$ followed by $\mathrm{Nh}\left(r^{2}=\right.$ $0.23)$, Hh $\left(r^{2}=0.16\right)$ and $\mathrm{Hl}\left(r^{2}=0.15\right) \cdot \delta^{18} \mathrm{O}$ of $\mathrm{Nn}$ category shows very poor correlation with temperature $\left(r^{2}=0.0\right)$ and precipitation $\left(r^{2}=\right.$ $0.02)$. $\delta^{18} \mathrm{O}$ of $\mathrm{Ll}$ category shows better correlation with precipitation $\left(r^{2}=0.75\right)$ followed by Hh $\left(r^{2}=0.16\right)$ and $\operatorname{Ln}\left(r^{2}=0.13\right) \cdot \delta^{18} \mathrm{O}$ of Ll category shows best correlation with relative humidity $\left(r^{2}=0.85\right)$ followed by $\mathrm{Hh}\left(r^{2}=0.31\right)$ and Nn $\left(r^{2}=0.22\right)$. This suggests that the temperature and precipitation amount are not dominant factors affecting the $\delta^{18} \mathrm{O}$ and d-excess of precipitation with normal isotopic composition $(\mathrm{Nn})$ (table 3).

The lowering of temperature with increasing elevation in mountainous regions usually leads to the enhanced condensation and therefore progressive depletion in heavy isotopes of precipitation with altitude widely known as altitude effect. In the present study, the altitude shows a very good correlation $\left(r^{2}=0.73\right)$ with average $\delta^{18} \mathrm{O}$ of the precipitation sites located above $1000 \mathrm{~m}$ above mean sea level (figure 6) indicating that the isotopic composition of precipitation is significantly influenced by the orographic lifting. The altitude
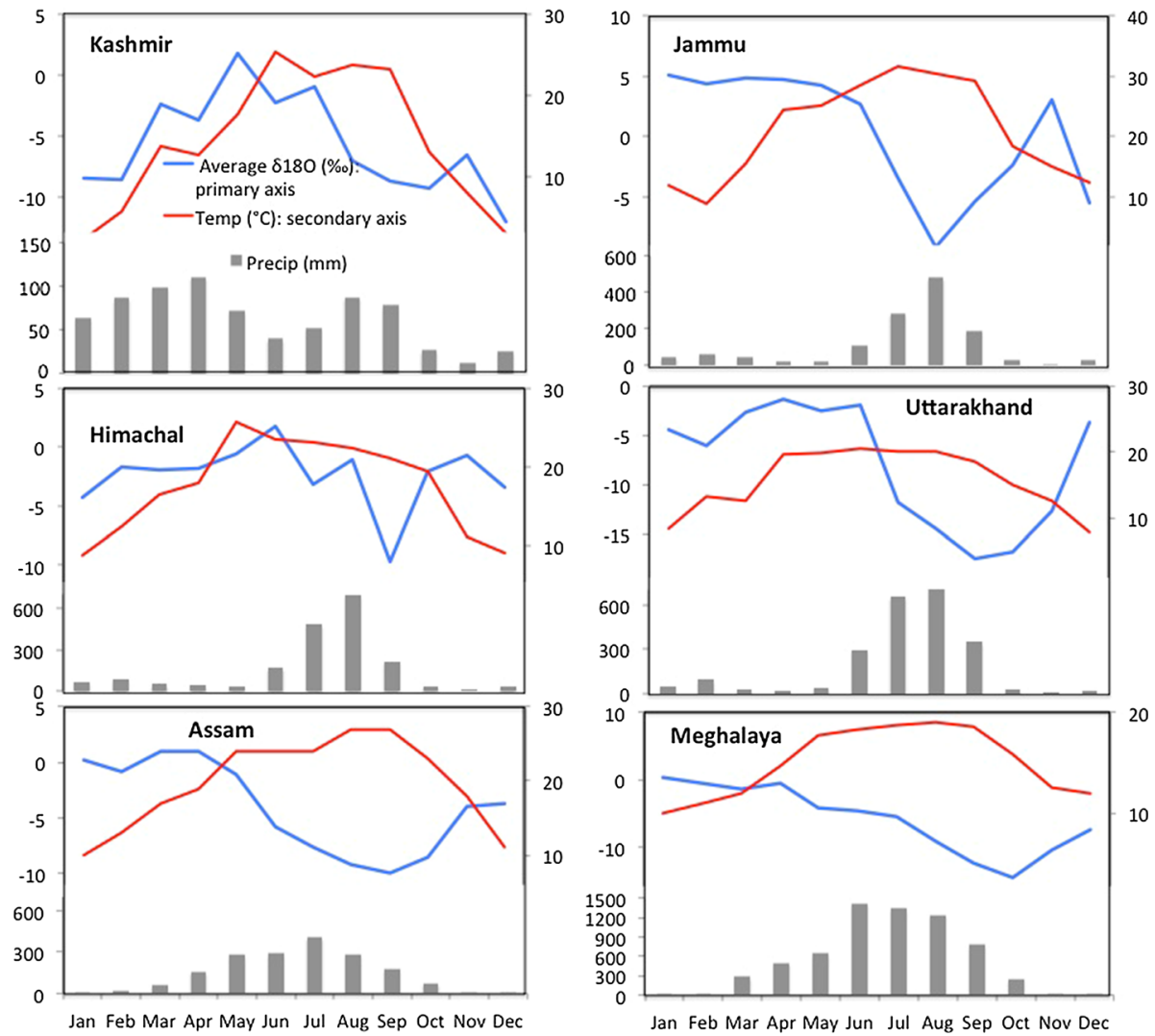

Figure 5. Average monthly $\delta^{18} \mathrm{O}$ and its relationship with average ambient temperature and precipitation in different regions of the Himalayas. 

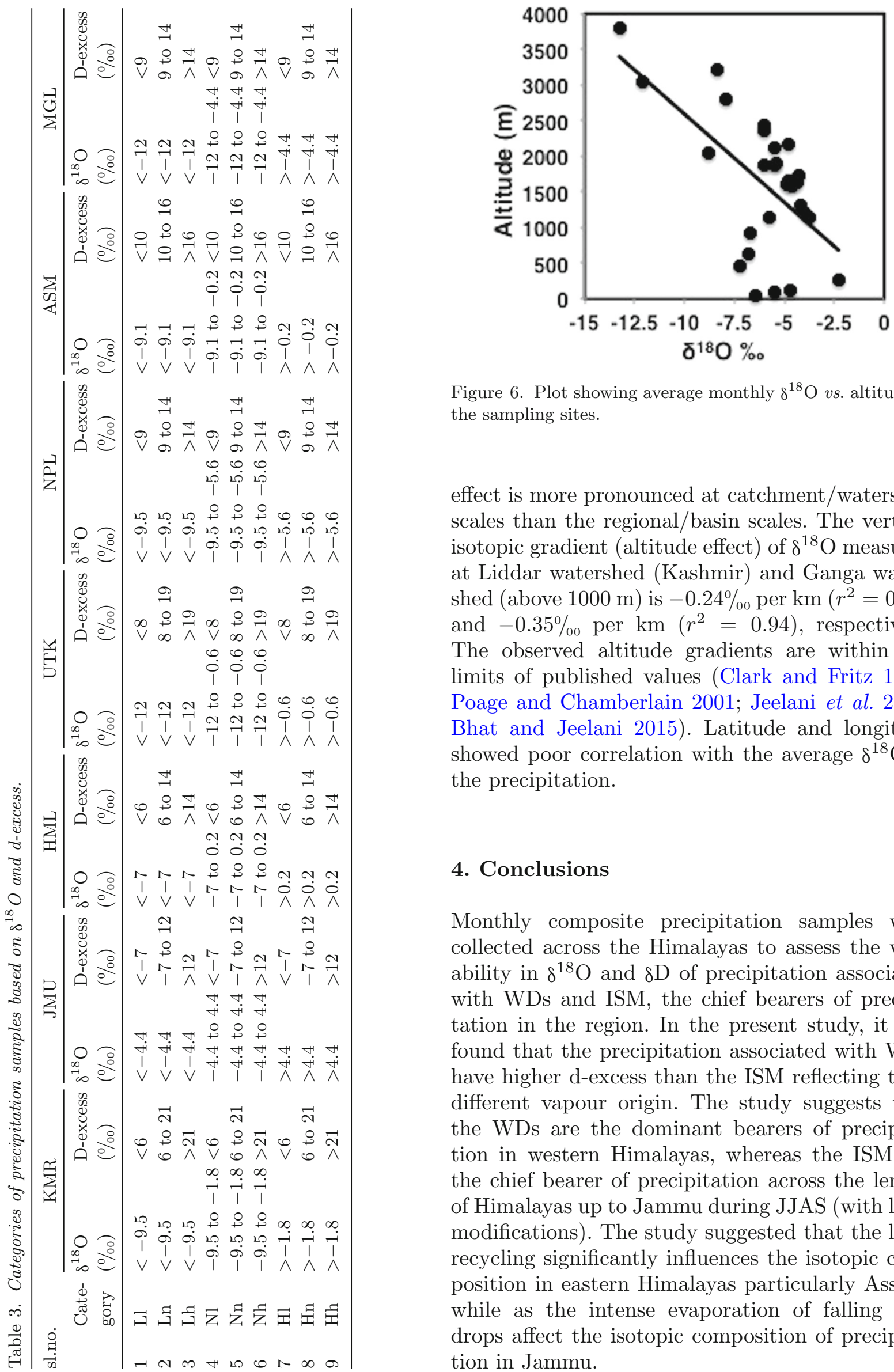

Figure 6. Plot showing average monthly $\delta^{18} \mathrm{O}$ vs. altitude of the sampling sites.

effect is more pronounced at catchment/watershed scales than the regional/basin scales. The vertical isotopic gradient (altitude effect) of $\delta^{18} \mathrm{O}$ measured at Liddar watershed (Kashmir) and Ganga watershed (above $1000 \mathrm{~m}$ ) is $-0.24 \%$ per $\mathrm{km}\left(r^{2}=0.88\right)$ and $-0.35 \%$ per $\mathrm{km}\left(r^{2}=0.94\right)$, respectively. The observed altitude gradients are within the limits of published values (Clark and Fritz 1997; Poage and Chamberlain 2001; Jeelani et al. 2010; Bhat and Jeelani 2015). Latitude and longitude showed poor correlation with the average $\delta^{18} \mathrm{O}$ of the precipitation.

\section{Conclusions}

Monthly composite precipitation samples were collected across the Himalayas to assess the variability in $\delta^{18} \mathrm{O}$ and $\delta \mathrm{D}$ of precipitation associated with WDs and ISM, the chief bearers of precipitation in the region. In the present study, it was found that the precipitation associated with WDs have higher d-excess than the ISM reflecting their different vapour origin. The study suggests that the WDs are the dominant bearers of precipitation in western Himalayas, whereas the ISM are the chief bearer of precipitation across the length of Himalayas up to Jammu during JJAS (with local modifications). The study suggested that the local recycling significantly influences the isotopic composition in eastern Himalayas particularly Assam, while as the intense evaporation of falling rain drops affect the isotopic composition of precipitation in Jammu. 


\section{Acknowledgements}

Part of the sampling and analyses discussed in this study was undertaken under the aegis of IWIN National Program funded jointly by the Department of Science and Technology (DST), Govt. of India, vide Grant No. IR/S4/ESF-05/2004 and the Physical Research Laboratory (PRL). Authors acknowledge the support of DST and PRL with gratitude. The valuable inputs and suggestions provided by the anonymous reviewers have improved the quality of the manuscript.

\section{References}

Agnihotri C L and Singh M S 1982 Satellite study of western disturbances; Mausam 33(2) 249-254.

Araguás-Araguás L, Froehlich K and Rozanski K 2000 Deuterium and oxygen-18 isotope composition of precipitation and atmospheric moisture; Hydrol. Process. 14(8) 13411355.

Bhat N A and Jeelani G 2015 Delineation of the recharge areas and distinguishing the sources of karst springs in Bringi watershed, Kashmir Himalayas using hydrochemistry and environmental isotopes; J. Earth Syst. Sci. 124(8) 1667-1676.

Breitenbach S F M, Adkins J F, Meyer H, Marwan N, Kumar K K and Haug G H 2010 Strong influence of water vapour source dynamics on stable isotopes in precipitation observed in southern Meghalaya, NE India; Earth Planet. Sci. Lett. 292 212-220.

Clark I and Fritz P 1997 Environmental Isotopes in Hydrogeology; Lewis Publishers, New York.

Craig H 1961 Isotope variations in meteoric waters; Science 133 1702-1703.

Dansgaard W 1964 Stable isotopes in precipitation; Tellus 16 436-468.

Dai A 2006 Recent climatology, variability, and trends in global surface humidity; J. Clim. 19 3589-3606.

Das P K 2005 The Monsoons; National Book Trust of India, New Delhi, 254p.

Deshpande R D and Gupta S K 2012 Oxygen and hydrogen isotopes in hydrological cycle: New data from IWIN National Programme; Proc. Indian Nat. Sci. Acad. 78(3) 321-331.

Deshpande R D, Bhattacharya S K, Jani R A and Gupta S K 2003 Distribution of oxygen and hydrogen isotopes in shallow groundwaters from southern India: Influence of dual monsoon system; J. Hydrol. 271 226-239.

Dhar O N, Kulkarni A K and Sangam E B 1984 Some aspects of winter \& monsoon rainfall distribution over the Garhwal-Kumaon Himalaya: A brief appraisal; Himal. Res. Dev. 2 10-19.

Dimri A P, Mohanty U C and Mandal M 2004 Simulation of heavy precipitation associated with an intense western disturbance over western Himalayas; Nat. Hazards 31 499-521.

Gadgil S 2003 The Indian monsoon and its variability; Ann. Rev. Earth Planet. Sci. 31 429-467.
Gajurel A P, France-Lanord C, Huyghe P, Guilmette C and Gurung D $2006 \mathrm{C}$ and O isotope compositions of modern fresh-water mollusc shells and river waters from the Himalaya and Ganga plain; Chem. Geol. 233 156-183.

Gat J R 1996 Oxygen and hydrogen isotopes in the hydrologic cycle; Ann. Rev. Earth Planet. Sci. 24 225-262.

Gat J R and Carmi I 1970 Evolution of the isotopic composition of atmospheric waters in the Mediterranean Sea area; J. Geophys. Res. 75 3039-3048.

Jeelani G, Kumar U S and Kumar B 2013 Variation of $\delta^{18} \mathrm{O}$ and $\delta \mathrm{D}$ in precipitation and stream waters across the Kashmir Himalaya (India) to distinguish and estimate the seasonal sources of stream flow; J. Hydrol. 481 157-165.

Jeelani G, Bhat N A and Shivanna K 2010 Use of ${ }^{18} \mathrm{O}$ tracer to identify stream and spring origins of a mountainous catchment: A case study from Liddar watershed, western Himalaya, India; J. Hydrol. 393 257-264.

Johnsen S, Dansgaard J W and White J W C 1989 The origin of Arctic precipitation under present and glacial conditions; Tellus Set B 4lB 452-468.

Jouzel J and Merlivat L 1984 Deuterium and oxygen 18 in precipitation: Modeling of the isotopic effects during snow formation; J. Geophys. Res. Atmos. 89(D7)11,749-11,757

Kendall C and Coplen T B 2001 Distribution of oxygen-18 and deuterium in river waters across the United States; Hydrol. Process. 151 363-1393.

Kumar B, Rai S P, Kumar U S, Verma S K, Garg P, Kumar S V V, Jaiswal R, Purendra B K, Kumar S R and Pande N G 2010 Isotopic characteristics of Indian precipitation; Water Resour. Res. 46 1-15.

Lai C T and Ehleringer R J R 2010 Deuterium excess reveals diurnal sources of water vapor in forest air; Oecologia 165 213-223.

Madhura R K, Krishnan R, Revadekar J V, Mujumdar M and Goswami B N 2015 Changes in western disturbances over the western Himalayas in a warming environment; Clim. Dyn. 44 1157-1168.

Maurya A S, Shah M, Deshpande R D, Bhardwaj R M, Prasad A and Gupta S K 2011 Hydrograph separation and precipitation source identification using stable water isotopes and conductivity: River Ganga at Himalayan foothills; Hydrol. Process. 25 1521-1530.

Maurya A S, Shah M, Deshpande R D and Gupta S K 2009 Protocol for $\delta^{18} \mathrm{O}$ and $\delta \mathrm{D}$ analyses of water sample using Delta V plus IRMS in CF Mode with Gas Bench II for IWIN National Programme at PRL, Ahmedabad; In: Proceedings of the $11^{\text {th }}$ ISMAS Triennial Conference of Indian Society for Mass Spectrometry Hyderabad and Mumbai.

Medina S, Houze R A, Kumar A and Niyogi D 2010 Summer monsoon convection in the Himalayan region: Terrain and land cover effects; Quart. J. Roy. Meteorol. Soc. 136(648) 593-616.

Merlivat L and Jouzel J 1979 Global climatic interpretation of the deuterium-oxygen 18 relationship for precipitation; J. Geophys. Res., 84 5029-5033.

Nikam B R, Kumar P, Garg V, Thakur P K and Aggarwal S P 2014 Comparative evaluation of different potential Evapotranspiration estimation approaches; Int. J. Res. Eng. Techn. 3(6) 544-552.

Pisharoty P R and Desai B N 1956 Western disturbances and Indian weather; Indian J. Meteorol. Geophys. 8 333-338. 
Poage M A and Chamberlain C P 2001 Empirical relationships between elevation and the stable isotope composition of precipitation and surface waters: Considerations for studies of paleoelevation change; Am. J. Sci. 301(1) $1-15$.

Rai S P, Purashothaman P, Kumar B, Jacob N and Rawat Y S 2014 Stable isotopic composition of precipitation in the River Bhagirathi Basin and identification of source vapour; Environ. Earth Sci. 71 4835-4847.

Rao B B, Sandeep V M, Rao V U M and Venkateswarlu B 2012 Potential evapotranspiration estimation for Indian conditions: Improving accuracy through calibration coefficients, Tech. Bull. No. 1/2012, National Initiative on Climate Resilient Agricultre (NICRA), All India Coordinated Research Project on Agrometeorology Central Research Institute for Dryland Agriculture Santoshnagar, Saidabad, Hyderabad, AP, India.

Ranade A A, Singh N, Singh H N and Sontakke N A 2007 Indian Characteristics of Hydrological Wet Season over Different River Basins of India, Contribution from IITM

Corresponding editor: A K SAHAI
Research Report No. RR-119 Indian Institute of Tropical Meteorology Pune, India.

Rao Y P 1976 Southwest monsoon; Meteorol. Monogr. Synoptic Meteorol 1/1976, India Meteorological Department, Delhi, India.

Rozanski K, Araguás-Araguás L and Gonfiantini R 1993 Climate change in continental isotopic records, American Geophysical Union, Washington DC, pp. 1-36.

Siegenthaler U and Oeschger H 1980 Correlation of ${ }^{18} \mathrm{O}$ in precipitation with temperature and altitude; Nature 285 314-317.

Warrier C U, Babu M P, Manjula P, Velayudhan K T, Hameed A S and Vasu K 2010 Isotopic characterization of dual monsoon precipitation-evidence from Kerala, India; Curr. Sci. 98(11) 1487-1495.

Yurtsever Y and Gat J 1981 Atmospheric waters; In: Stable Isotope Hydrology: Deuterium and Oxygen-18 in the Water Cycle (eds) Gat J R and Gonfiantini R, IAEA Vienna Austria, pp. 103-142. 